\title{
Near-IR laser generation of a high-energy conformer of L-alanine and the mechanism of its decay in a low-temperature nitrogen matrix
}

Cláudio M. Nunes, Leszek Lapinski, Rui Fausto, and Igor Reva

Citation: The Journal of Chemical Physics 138, 125101 (2013); doi: 10.1063/1.4795823

View online: https://doi.org/10.1063/1.4795823

View Table of Contents: http://aip.scitation.org/toc/jcp/138/12

Published by the American Institute of Physics

\section{Articles you may be interested in}

Spontaneous tunneling and near-infrared-induced interconversion between the amino-hydroxy conformers of cytosine

The Journal of Chemical Physics 136, 064511 (2012); 10.1063/1.3683217

Formic and acetic acids in a nitrogen matrix: Enhanced stability of the higher-energy conformer The Journal of Chemical Physics 133, 144507 (2010); 10.1063/1.3484943

Conformers, infrared spectrum, UV-induced photochemistry, and near-IR-induced generation of two rare conformers of matrix-isolated phenylglycine

The Journal of Chemical Physics 141, 154306 (2014); 10.1063/1.4897526

Effects of the matrix and intramolecular interactions on the stability of the higher-energy conformers of 2fluorobenzoic acid

The Journal of Chemical Physics 146, 124305 (2017); 10.1063/1.4978794

Tetrazole acetic acid: Tautomers, conformers, and isomerization

The Journal of Chemical Physics 140, 064306 (2014); 10.1063/1.4864119

Conformational changes in matrix-isolated 6-methoxyindole: Effects of the thermal and infrared light excitations The Journal of Chemical Physics 144, 124306 (2016); 10.1063/1.4944528

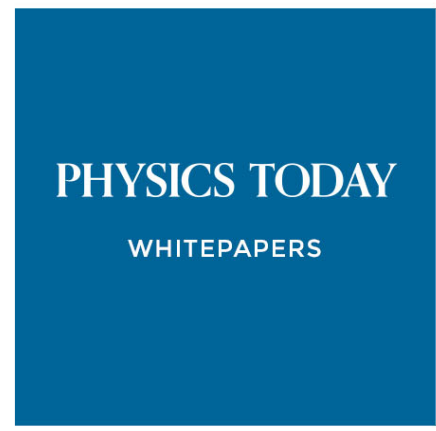

ADVANCED LIGHT CURE ADHESIVES

Take a closer look at what these environmentally friendly adhesive systems can do

\section{READ NOW}

PRESENTED BY Q MASTERBOND 


\title{
Near-IR laser generation of a high-energy conformer of L-alanine and the mechanism of its decay in a low-temperature nitrogen matrix
}

\author{
Cláudio M. Nunes, ${ }^{1}$ Leszek Lapinski, ${ }^{1,2}$ Rui Fausto, ${ }^{1}$ and Igor Reva ${ }^{1, a)}$ \\ ${ }^{1}$ Department of Chemistry, University of Coimbra, 3004-535 Coimbra, Portugal \\ ${ }^{2}$ Institute of Physics, Polish Academy of Science, Al. Lotnikow 32/46, 02-668 Warsaw, Poland
}

(Received 19 January 2013; accepted 2 March 2013; published online 28 March 2013)

\begin{abstract}
Monomers of L-alanine (ALA) were isolated in cryogenic nitrogen matrices at $14 \mathrm{~K}$. Two conformers were identified for the compound trapped from the gas-phase into the solid nitrogen environment. The potential energy surface (PES) of ALA was theoretically calculated at the MP2 and QCISD levels. Twelve minima were located on this PES. Seven low-energy conformers fall within the $0-10 \mathrm{~kJ} \mathrm{~mol}^{-1}$ range and should be appreciably populated in the equilibrium gas phase prior to deposition. Observation of only two forms in the matrices is explained in terms of calculated barriers to conformational rearrangements. All conformers with the $\mathrm{O}=\mathrm{C}-\mathrm{O}-\mathrm{H}$ moiety in the cis orientation are separated by low barriers and collapse to the most stable form $\mathbf{I}$ during deposition of the matrix onto the low-temperature substrate. The second observed form $\mathbf{I I}$ has the $\mathrm{O}=\mathrm{C}-\mathrm{O}-\mathrm{H}$ group in the trans orientation. The remaining trans forms have very high relative energies (between 24 and $30 \mathrm{~kJ}$ $\mathrm{mol}^{-1}$ ) and are not populated. The high-energy trans form VI, that differs from I only by rotation of the $\mathrm{OH}$ group, was found to be separated from other conformers by barriers that are high enough to open a perspective for its stabilization in a matrix. The form VI was photoproduced in situ by narrow-band near-infrared irradiation of the samples at $6935-6910 \mathrm{~cm}^{-1}$, where the first overtone of the $\mathrm{OH}$ stretching vibration in form $\mathbf{I}$ appears. The photogenerated form VI decays in $\mathrm{N}_{2}$ matrices back to conformer $\mathbf{I}$ with a characteristic decay time of $\sim 15 \mathrm{~min}$. The mechanism of the $\mathbf{V I} \rightarrow \mathbf{I}$ relaxation is rationalized in terms of the proton tunneling. (c) 2013 American Institute of Physics. [http://dx.doi.org/10.1063/1.4795823]
\end{abstract}

\section{INTRODUCTION}

Amino acids are of great relevance, since they are the building blocks of central molecular elements of life. ${ }^{1}$ The structural studies of gas-phase amino acids, where they exist in non-ionized neutral form (in contrast with the zwitterionic form of the solid-phase), provided vital information to understand the dynamics and the proprieties of peptides and proteins backbones. ${ }^{2}$ Due to the rotational flexibility of neutral amino acids several conformational forms may arise, which result from the balance between stabilizing effects of hyperconjugation and intramolecular $\mathrm{H}$-bonds, and destabilizing steric effects as well as the lone electron pairs repulsion. Therefore, especially taking into account the involved subtle different interactions, understanding the conformational landscape of amino acids, establishing their structure and properties, is still an important goal to be achieved and an active research topic.

Alanine $\left(\mathrm{H}_{2} \mathrm{~N}-\mathrm{CH}\left(\mathrm{CH}_{3}\right)-\mathrm{CO}_{2} \mathrm{H}\right)$ is the simplest chiral natural amino acid and one of the most important. Therefore, it is not surprising that several theoretical ${ }^{3-10}$ and experimental ${ }^{11-18}$ studies on alanine neutral form have been performed in order to understand its structure and conformational dynamics. One of the first important experimental studies was carried out using free-jet microwave spectroscopy and allowed the identification of two alanine

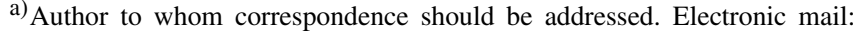
reva@qui.uc.pt. conformers, I and IIa (Fig. 1), and the determination of their rotational constants and dipole moments. ${ }^{11}$ The same conformers, I and IIa, were also identified for alanine trapped in a low-temperature argon matrix, and the infrared spectroscopic signatures of these forms have been established. ${ }^{12}$ Furthermore, the rotational spectrum of gas-phase alanine was obtained using laser-ablation Fourier transform microwave spectroscopy and the structures of conformers I and IIa were experimentally determined. ${ }^{14}$ From the theoretical studies on gas-phase alanine, it has been predicted the existence of up to 13 possible conformers. ${ }^{3-8}$ Their geometries, relative energies, and several spectroscopic proprieties were estimated at the HF, MP2, and B3LYP levels of theory using different basis sets. ${ }^{3-8}$ The two lowest energy alanine conformers, I and IIa, were also studied using rigorous $\operatorname{CCSD}(\mathrm{T}) / \mathrm{cc}-\mathrm{pVTZ}$ $a b$ initio calculations, and their semi-experimental equilibrium structures were determined by the refinement of experimental rotational constants data. ${ }^{9}$

If only theoretical relative energies are considered, the corresponding gas-phase equilibrium populations, derived from Boltzmann statistics, cannot be reconciled with the population of alanine conformers found in the experimental studies. Indeed, some conformers that according to their computed relative energies should significantly contribute to the gas-phase conformational equilibrium have never been experimentally detected with certainty. These experimental results have been interpreted (sometimes with the aid of the computation of the relevant potential-energy-surface regions $)^{5,14}$ 


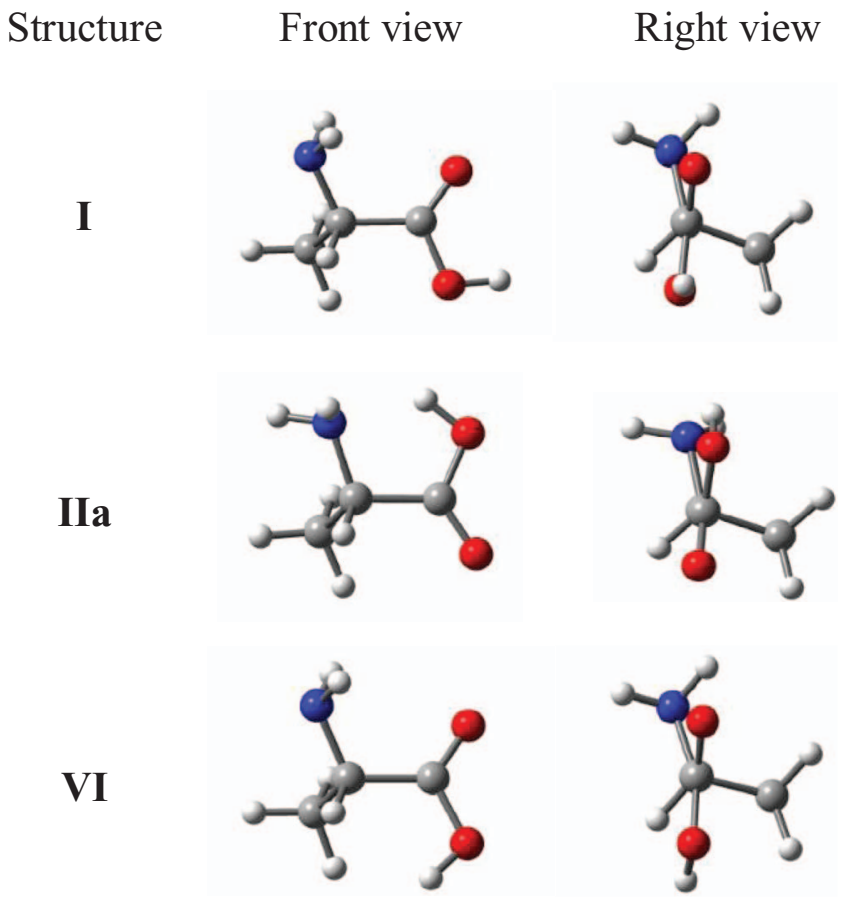

FIG. 1. Structures of L-alanine conformers (I, IIa, and VI). Color codes: grey $-\mathrm{C}$, red $-\mathrm{O}$, blue $-\mathrm{N}$, white $-\mathrm{H}$. These forms are the most important in the context of the current study. Structures and optimized geometries of all 13 conformers of L-alanine are given in the supplementary material. ${ }^{42}$

as a consequence of conformational relaxation to the more stable, lower-energy conformational forms. Actually, in two independent studies, one using Raman spectroscopy ${ }^{17}$ of jetcooled alanine and the other using valence photoelectron spectroscopy, ${ }^{18}$ the identification of four gas-phase alanine conformers (I, IIa, IIb, and IIIa) has been claimed. Notwithstanding, the unambiguous identification of IIb and IIIa is still questionable, as will be shown below.

The lack of unequivocal identification of low-energy alanine conformers other than I and IIa has never been sufficiently rationalized hitherto. In the current work, we performed a detailed analysis of the full potential-energy surface (PES) of alanine, in order to localize all the conformational minima as well as to estimate the barriers separating them. The resulting theoretical picture was then confronted with the results obtained in the experimental study of L-alanine isolated in low-temperature nitrogen matrices. Moreover, a new conformational high-energy form VI of the compound has been generated by narrowband near-IR tunable selective vibrational excitation of the most stable conformer $\mathbf{I}$. The relaxation of the photogenerated form VI back to $\mathbf{I}$, occurring by hydrogen-atom tunneling mechanism, has also been investigated.

\section{EXPERIMENTAL PROCEDURES}

\section{A. Materials}

A commercial L-alanine (ALA) sample (Aldrich, $\geq 98 \%$ purity) and nitrogen gas (Air Liquide, N60 purity) were used.

\section{B. Matrix-isolation}

For preparing matrices, a solid sample of ALA was sublimated (at $\sim 400 \mathrm{~K}$ ) using a miniature glass oven placed in the vacuum chamber of the cryostat. The vapors of the compound were then deposited, simultaneously with a large excess of nitrogen gas, onto a cold $(14 \mathrm{~K}) \mathrm{CsI}$ substrate. The temperature of the CsI window was measured directly by a silicon diode sensor, connected to a digital controller (Scientific Instruments, model 9650-1), with an accuracy of $0.1 \mathrm{~K}$. In all experiments, an APD Cryogenics closed-cycle helium refrigeration system with a DE-202A expander was used.

\section{FTIR spectroscopy}

The mid-IR spectra $\left(4000-400 \mathrm{~cm}^{-1} ; 0.5 \mathrm{~cm}^{-1}\right.$ resolution) were obtained using a Thermo Nicolet 6700 Fourier transform infrared spectrometer, equipped with a deuterated triglycine sulfate (DTGS) detector and a $\mathrm{Ge} / \mathrm{KBr}$ beam splitter. The near-IR ( $8500-2000 \mathrm{~cm}^{-1} ; 1 \mathrm{~cm}^{-1}$ resolution) spectra were recorded using the same spectrometer and the detector but equipped with a $\mathrm{CaF}_{2}$ beamsplitter. Modifications of the sample compartment of the spectrometer were made in order to accommodate the cryostat head and allow an efficient purging of the system by a continuous stream of dry air to avoid interference from atmospheric $\mathrm{H}_{2} \mathrm{O}$ and $\mathrm{CO}_{2}$. To protect matrices from light with wavenumbers greater than $2100 \mathrm{~cm}^{-1}$, a standard Edmund Optics longpass filter was used (transmission cut-off $4.73 \mu \mathrm{m})$.

\section{Near-IR laser irradiation experiments}

Matrices were irradiated using narrowband (fwhm $\sim 0.2 \mathrm{~cm}^{-1}$ ) tunable near-IR light provided by the idler beam of a Quanta-Ray MOPO-SL pulsed optical parametric oscillator (pulse energy $10-12 \mathrm{~mJ}$, repetition rate $=10 \mathrm{~Hz}$, duration $=10 \mathrm{~ns}$ ) pumped with a pulsed $\mathrm{Nd}$ :YAG laser.

\section{E. Theoretical calculations}

All calculations were performed using the GAUSSIAN 09 program. ${ }^{19}$ The two-dimensional (2D) relaxed PES of ALA were exhaustively explored at the standard MP2/6$311++\mathrm{G}(\mathrm{d}, \mathrm{p})$ level of theory. The geometries of the local minima found were optimized and their harmonic vibrational frequencies were calculated using the same theory level, in order to characterize the nature of stationary points. Geometry optimizations and vibrational calculations were also performed at the B3LYP/aug-cc-pVTZ and the QCISD/6$311++\mathrm{G}(\mathrm{d}, \mathrm{p})$ levels of theory, as they are implemented in GAUSSIAN 09. In all cases, the TIGHT convergence criteria were used during geometry optimization. The B3LYP and MP2 vibrational frequencies were calculated analytically and QCISD frequencies were calculated numerically.

The harmonic vibrational frequencies, calculated at the B3LYP/aug-cc-pVTZ level and used in the analysis of experimental IR spectra, were all scaled by 0.98 , with exception of the $v(\mathrm{O}-\mathrm{H})$ and $v(\mathrm{~N}-\mathrm{H})$ modes which were scaled by a factor of 0.95 . The resulting frequencies, together with 

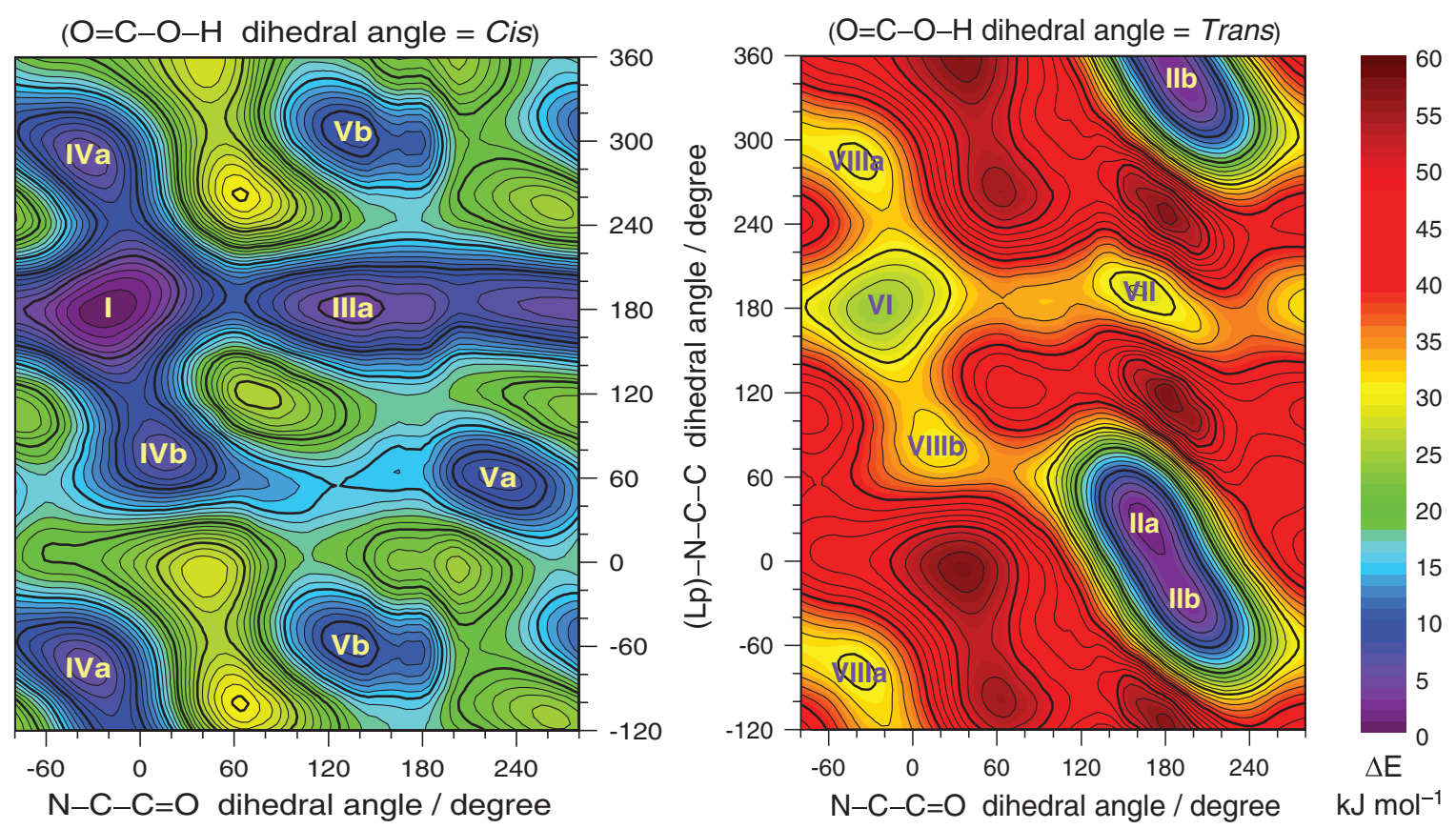

FIG. 2. Potential energy surface of ALA calculated at the MP2/6-311++G(d,p) level of theory, as a function of two dihedral angles, N-C $-\mathrm{C}=\mathrm{O}$ and ( $\mathrm{Lp})-\mathrm{N}-\mathrm{C}-\mathrm{C}$. These two dihedral angles were incrementally fixed with a step of $20^{\circ}$ and the remaining parameters were optimized. (Lp) stands for "lone pair" of the nitrogen atom and is defined as a direction in the plane bisecting the two $\mathrm{HNC}$ planes. Left: the dihedral $\mathrm{O}=\mathrm{C}-\mathrm{O}-\mathrm{H}$ angle was kept in the cis orientation (and optimized). Right: the dihedral $\mathrm{O}=\mathrm{C}-\mathrm{O}-\mathrm{H}$ angle was kept in the trans orientation (and optimized). The colored bar on the right side designates the relative energy which is defined relatively to the energy of form $\mathbf{I}$. The thin isoenergy lines are traced with steps of 1 and $2 \mathrm{~kJ} \mathrm{~mol}^{-1}$, while the bold isolines show relative energies multiple of 5 and $10 \mathrm{~kJ} \mathrm{~mol}^{-1}$, in the left and right panel, respectively. The Roman numbers from I to VIII designate local minima, whose relative energies are collected in Table I. Note that the two surfaces extend for $360^{\circ}$ horizontally and $480^{\circ}$ vertically.

the calculated intensities, were used to simulate the spectra shown in the figures. In these simulations, the absorptions were broadened by Lorentzian profiles ( $\mathrm{fwhm}=4 \mathrm{~cm}^{-1}$ ) and centered at the calculated (scaled) frequencies using the SYNSPEC software. ${ }^{20}$ Note that the peak intensities in the simulated spectra (shown in units of "relative intensity") differ from the calculated intensities (in $\mathrm{km} \mathrm{mol}^{-1}$ ), because they were set to satisfy the condition that the integrated band area in simulated spectrum corresponds to the calculated infrared intensity.

The theoretical normal modes were analyzed by carrying out the potential energy distribution (PED) calculations, performed according to the procedure described in Refs. 21 and 22. The set of internal coordinates used in the PED analysis was defined following the recommendations of Pulay et al. ${ }^{23}$ These coordinates are listed in Table S1 (in the supplementary material). Cartesian force constants were transformed into the force constants with respect to the molecule-fixed internal coordinates. Potential-energy-distribution matrices have been calculated, and the elements of these matrices greater than 10\% are given in Table II, and Tables S2 and S3 (supplementary material). ${ }^{42}$

\section{RESULTS AND DISCUSSION}

\section{A. Potential energy surface of L-alanine}

The ALA molecule has three main conformational degrees of freedom, related with the internal rotation around the
$\mathrm{C}-\mathrm{O},(\mathrm{O}=) \mathrm{C}-\mathrm{C}_{\alpha}$, and $\mathrm{C}_{\alpha}-\mathrm{N}$ single bonds, which give rise to the existence of several conformational structures. Previous theoretical studies located up to 13 possible minima on the PES of alanine, and the analysis of the relative energies of these minima as well as of the geometry of the corresponding structures have also been reported. ${ }^{3-8}$ However, in order to understand and recognize the nature of ALA conformers that would be relevant from the viewpoint of the experiments carried out in the present work, a detailed investigation of the PES of ALA requires not only characterization of the local minima but also of the barriers connecting (or separating) them.

As it was shown in all previous theoretical studies, the $\mathrm{O}=\mathrm{C}-\mathrm{O}-\mathrm{H}$ dihedral angle in ALA adopts only two orientations, cis and trans. Considering these two orientations, relaxed PES scans were performed on 2D grids of points as a function of two dihedral angles, $\mathrm{N}-\mathrm{C}-\mathrm{C}=\mathrm{O}$ and (Lp) $-\mathrm{N}-\mathrm{C}-\mathrm{C}$ ("Lp" stands for the lone pair of the nitrogen atom, which was defined as a direction in the plane bisecting the two HNC planes), which were incrementally fixed with a step of $20^{\circ}$ while the remaining parameters were optimized.

Figure 2 presents the 2D contour maps of the two resulting PES of ALA calculated at MP2/6-311++G(d,p) level of theory. Twelve minima were identified on the PES, and the structures of the corresponding conformations are graphically presented in Fig. S1 (supplementary material). ${ }^{42}$ The Cartesian coordinates of all minimum-energy structures of ALA calculated at different levels of theory are also given in the supplementary material. The relative electronic energies $(\Delta E)$ 
TABLE I. Relative electronic energies $(\Delta \mathrm{E})$ and relative Gibbs energies at $400 \mathrm{~K}\left(\Delta \mathrm{G}_{400 \mathrm{~K}}\right)$ calculated at the B3LYP/aug-cc-pVTZ, MP2/6-311++G(d,p), and QCISD/6-311++G(d,p) levels of theory, and the equilibrium populations of ALA conformers estimated from the relative Gibbs energies at $400 \mathrm{~K}\left(\mathrm{P}_{400}\right){ }^{\mathrm{a}}$

\begin{tabular}{|c|c|c|c|c|c|c|c|c|c|}
\hline \multirow[b]{2}{*}{ Structure } & \multicolumn{3}{|c|}{ B3LYP } & \multicolumn{3}{|c|}{ MP2 } & \multicolumn{3}{|c|}{ QCISD } \\
\hline & $\Delta \mathrm{E}$ & $\Delta \mathrm{G}_{400 \mathrm{~K}}$ & $\mathrm{P}_{400}$ & $\Delta \mathrm{E}$ & $\Delta \mathrm{G}_{400 \mathrm{~K}}$ & $\mathrm{P}_{400}$ & $\Delta \mathrm{E}$ & $\Delta \mathrm{G}_{400 \mathrm{~K}}$ & $P_{400}$ \\
\hline I & 0.0 & 0.0 & 48.2 & 0.0 & 0.0 & 52.8 & 0.0 & 0.0 & 56.9 \\
\hline IIa & 0.2 & 3.8 & 15.6 & 0.7 & 5.1 & 11.5 & 3.1 & 7.5 & 6.0 \\
\hline IIb & 0.5 & $\mathrm{~b}$ & $\ldots$ & 2.0 & $\mathrm{~b}$ & $\ldots$ & 3.9 & $\mathrm{~b}$ & $\ldots$ \\
\hline IIIa & 4.8 & 4.3 & 13.4 & 4.0 & 4.6 & 13.3 & 4.3 & 4.9 & 12.9 \\
\hline IIIb & c & $\ldots$ & $\ldots$ & c & $\ldots$ & $\ldots$ & 5.4 & b & $\ldots$ \\
\hline IVa & 4.9 & 5.6 & 8.9 & 5.0 & 6.0 & 8.7 & 5.1 & 6.1 & 9.0 \\
\hline IVb & 5.5 & 6.3 & 7.3 & 6.1 & 7.3 & 5.9 & 6.0 & 7.4 & 6.2 \\
\hline Va & 8.2 & 8.4 & 3.9 & 7.4 & 8.3 & 4.4 & 6.7 & 7.9 & 5.2 \\
\hline Vb & 9.5 & 9.9 & 2.5 & 8.4 & 9.1 & 3.4 & 8.2 & 9.1 & 3.7 \\
\hline VI & 21.1 & 20.2 & 0.1 & 24.2 & 23.1 & 0.1 & 24.0 & 22.9 & 0.1 \\
\hline VII & 22.4 & 22.5 & 0.1 & 27.8 & 28.2 & 0.0 & 28.9 & 29.2 & 0.0 \\
\hline VIIIa & 25.5 & 25.3 & 0.0 & 27.8 & 28.9 & 0.0 & 28.9 & 28.9 & 0.0 \\
\hline VIIIb & 26.0 & 26.0 & 0.0 & 30.3 & 30.9 & 0.0 & 30.1 & 30.8 & 0.0 \\
\hline
\end{tabular}

${ }^{\text {a }}$ Relative energies are given in $\mathrm{kJ} \mathrm{mol}^{-1}$, populations in $\%$. The calculated electronic energy of the most stable conformer $\mathbf{I}$ in atomic units is $-323.885253,-322.988867$, and -323.027708, at B3LYP/aug-cc-pVTZ, MP2/6-311++G(d,p), and QCISD/6$311++\mathrm{G}(\mathrm{d}, \mathrm{p})$ levels of theory, respectively. The graphical representation of the ALA structures is given in Fig. S1. ${ }^{42}$

${ }^{\mathrm{b}}$ The structures IIb and IIIb were not considered in the estimation of conformational populations, as discussed in the text.

${ }^{\mathrm{c}}$ The structure IIIb was not found as a minimum on the PES at B3LYP/aug-cc-pVTZ and MP2/6-311++G(d,p) levels of theory.

and the relative Gibbs energies at $400 \mathrm{~K}\left(\Delta \mathrm{G}_{400 \mathrm{~K}}\right)$, calculated at the B3LYP/aug-cc-pVTZ, MP2/6-311++G(d,p), and QCISD/6-311++G(d,p) levels of theory, and the corresponding equilibrium populations of ALA conformers estimated from the relative Gibbs energies at $400 \mathrm{~K}\left(\mathrm{P}_{400}\right)$ are provided in Table I. The nomenclature used in the present work is in accordance with that suggested by Császár, ${ }^{6}$ where the alanine structures 1-13 correspond to I, IIa, IIb, IIIa, IIIb, IVa, IVb, Va, Vb, VI, VII, VIIIa, and VIIIb in an increasing order of electronic energy.

As shown in the right part of Fig. 2, the PES of ALA with the trans $\mathrm{O}=\mathrm{C}-\mathrm{O}-\mathrm{H}$ arrangement indicates that conformers VI, VII, VIIIa, VIIIb have relative energies higher by more than $20 \mathrm{~kJ} \mathrm{~mol}^{-1}$, with respect to the energy of conformer I. The only low-energy minimum found on this surface is that corresponding to the structure IIa/IIb. Therefore, it can be anticipated that conformers VI, VII, VIIIa, VIIIb have negligible thermal populations in the alanine gas-phase equilibrium $(<0.1 \%$, see Table I), and then should not appear in a freshly deposited sample. Another important feature of this PES is that structures IIa and IIb are separated by a very low energy barrier. The 2D-PES (Fig. 2, right) shows that structures IIa and IIb are confined in a narrow area of the dihedral angles, and also that the two dihedral angles change simultaneously along the lowest-energy path connecting IIa and IIb.

In order to demonstrate this better, two relaxed onedimensional (1D) potential energy scans of the PES were calculated at the MP2/6-311++G(d,p) level of theory in the vicinity of structures IIa/IIb (Fig. 3). In one of them, the $\mathrm{N}-\mathrm{C}-\mathrm{C}=\mathrm{O}$ dihedral angle was used as a driving coordinate (red trace and red X-axis in Fig. 3(a)). In the other 1D-scan, the (Lp) $-\mathrm{N}-\mathrm{C}-\mathrm{C}$ dihedral angle was used as a driving coordinate (blue trace and blue $\mathrm{X}$-axis in Fig. 3(a)). The obtained 1D potential energy profiles (red and blue) show an

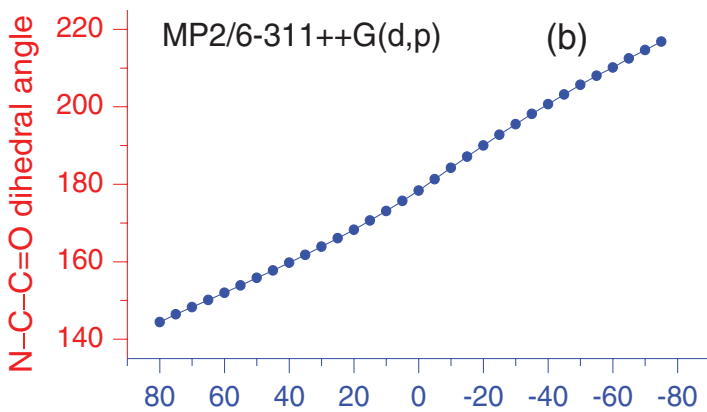

(Lp) $-\mathrm{N}-\mathrm{C}-\mathrm{C}$ dihedral angle / degree

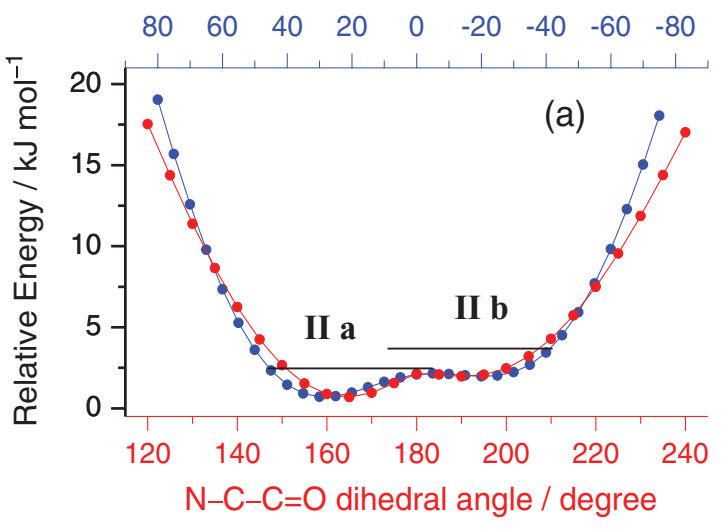

FIG. 3. (a) Relaxed potential energy profiles calculated for ALA, at the MP2/6-311++G(d,p) level of theory, in the vicinity of conformer II, as functions of the $\mathrm{N}-\mathrm{C}-\mathrm{C}=\mathrm{O}$ dihedral angle (red) and ( $\mathrm{Lp})-\mathrm{N}-\mathrm{C}-\mathrm{C}$ dihedral angle (blue). "Lp" stands for the $\mathrm{NH}_{2}$ group lone pair and is defined as described in the caption of Fig. 1. Horizontal black lines designate the ground state vibrational energy levels for the $\mathrm{NH}_{2}$ torsional vibrations, corresponding to the IIa and IIb local minima. The relative MP2 electronic energies were calculated with respect to the energy of conformer I; (b) optimized values of the $\mathrm{N}-\mathrm{C}-\mathrm{C}=\mathrm{O}$ dihedral angle as a function of the (Lp) $-\mathrm{N}-\mathrm{C}-\mathrm{C}$ dihedral angle, showing almost linear correlation in the vicinity of conformer II. Note that axes of the same color designate the same coordinates across the frames. 
almost linear correspondence. This is especially obvious if the relaxed values of the $\mathrm{N}-\mathrm{C}-\mathrm{C}=\mathrm{O}$ dihedral angle are plotted as a function of the (Lp) $-\mathrm{N}-\mathrm{C}-\mathrm{C}$ dihedral angle (Fig. 3(b)), which shows that the two dihedral angles are not independent in the vicinity of forms $\mathbf{I} \mathbf{I a} / \mathbf{I I b}$. The implication is that the vibrational motion along any of the two coordinates (either torsion of the amino group or torsion of the carboxyl group) is equally important when analyzing this fragment of the PES. From this viewpoint, form IIb can be converted to IIa barrierlessly, since the barrier is only about $0.2 \mathrm{~kJ} \mathrm{~mol}^{-1}$. This energy barrier (IIb $\rightarrow$ IIa) stays below the zero-point vibrational energy of the related coordinates, as exemplified in Fig. 3 for the amino group torsional vibration (the calculated frequency is about $280 \mathrm{~cm}^{-1}$ or $3.5 \mathrm{~kJ} \mathrm{~mol}^{-1}$ ). In conformational terms this means that the IIa and IIb local minima coalesce into a single conformer which exercises a broad amplitude motion along the bottom of the potential energy well IIa/IIb.

In a matrix-isolation experiment, such a broad amplitude motion should result in a broadening of the absorption bands for form II. Equally important, at cryogenic temperatures $(\sim 14 \mathrm{~K}$ in this study), due to the energy difference between IIa and IIb (predicted to be 1.3 and $0.8 \mathrm{~kJ}$ $\mathrm{mol}^{-1}$, at the MP2 and QCISD levels, see Table I), the entire population within this minimum will shift towards IIa. In other experiments (such as experiments on ALA in gasphase) the consequence should be that form IIb cannot exist as a unique form independent of form IIa. To attain an even more precise theoretical description of this part of PES, we calculated 1D relaxed potential energy profiles in the vicinity of structures II at the QCISD/6-311++G(d,p) level of theory (Fig. S2). This calculation resulted in the same conclusion: there is no independent form IIb in a monomeric ALA molecule.

In contrast to the trans $\mathrm{O}=\mathrm{C}-\mathrm{O}-\mathrm{H}$ energy surface, the PES of ALA with a cis $\mathrm{O}=\mathrm{C}-\mathrm{O}-\mathrm{H}$ arrangement, shown in the left part of Fig. 2, indicates that all conformers found on this surface (i.e., I, IIIa, IVa, IVb, Va, and Vb) have low relative energies (below $10 \mathrm{~kJ} \mathrm{~mol}^{-1}$; see Table I). Here, a relatively flat potential energy region occurs in the vicinity of structures III. Due to this feature, only structure IIIa was found as the minimum in the calculations carried out at the B3LYP/aug-cc-pVTZ and MP2/6-311++G(d,p) levels of theory. This result stays in contrast to previous calculations at the Hartree Fock (HF) level of theory, where both IIIa and IIIb were found as minima. ${ }^{4,6}$ Actually, the present calculations performed at the high level of theory, QCISD/6-311++G(d,p), also indicate structure IIIb of ALA as a minimum on the PES. Nevertheless, as shown in Fig. 4, the relaxed 1D-scans of the PES in the vicinity of structures I, IIIa, and IIIb, as a function of the $\mathrm{N}-\mathrm{C}-\mathrm{C}=\mathrm{O}$ dihedral angle, calculated at the MP2/6-311++G(d,p) and QCISD/6-311++G(d,p) levels, suggest that structure IIIb is not a "true" ALA conformer, but rather an excited vibrational state of form I. This is because structure IIIb is not a minimum on the PES (at MP2 level) or, if it is a formal minimum (at QCISD level), the barrier for isomerization towards conformer I is only a few tenths of $\mathrm{kJ} \mathrm{mol}^{-1}$ from the zero-point vibrational energy along the reaction coordinate.

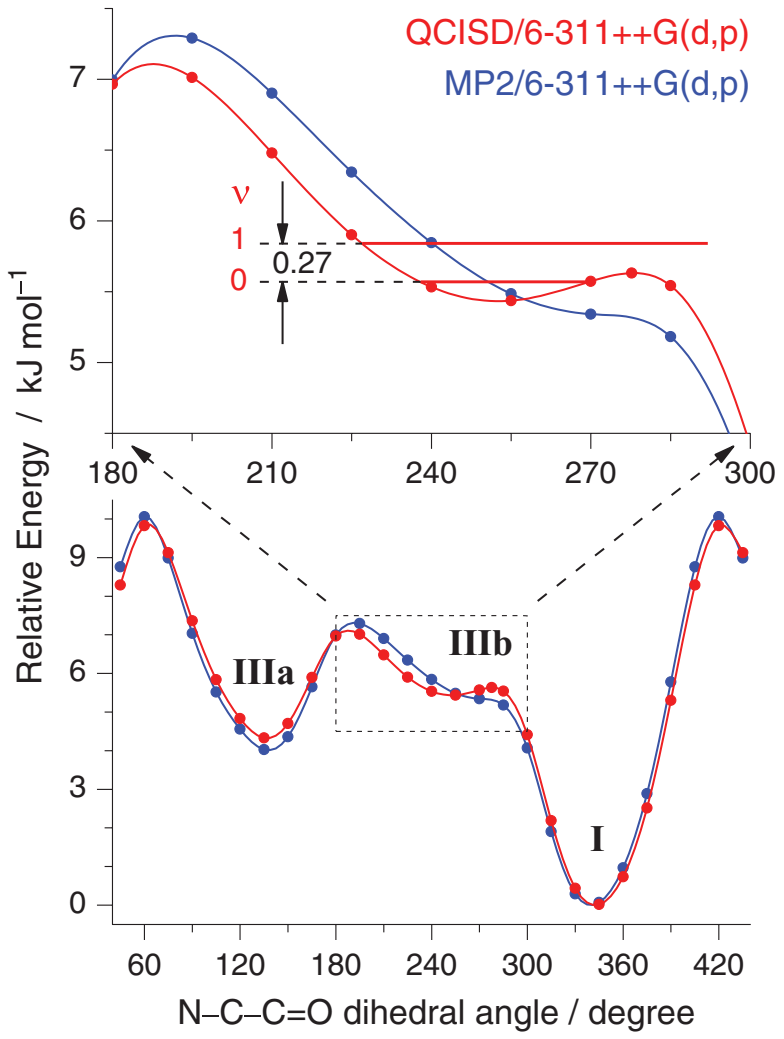

FIG. 4. Relaxed potential energy surface of ALA in the vicinity of structures I, IIIa, and IIIb calculated at the QCISD (red) and MP2 (blue) levels of theory as a function of the $\mathrm{N}-\mathrm{C}-\mathrm{C}=\mathrm{O}$ dihedral angle. The top frame is an enlarged view of the area designated with dashed rectangle (vicinity of IIIb) in the bottom frame. Horizontal red lines in the top frame designate the vibrational ground state (0) and the first excited vibrational state (1) of IIIb along the reaction coordinate $(v)$. The relative zero energy corresponds to the calculated energy of form $\mathbf{I}$.

If in the case of the ALA cis $\mathrm{O}=\mathrm{C}-\mathrm{O}-\mathrm{H}$ PES (Fig. 2; left) only the relative energies are taken into account, it could be expected that all the conformers found on that surface (I, IIIa, IVa, IVb, Va, and Vb) would non-negligibly contribute to the gas-phase conformational equilibrium of alanine at $400 \mathrm{~K}$ (Table I). However, when this gas-phase population is transferred into a low-temperature matrix, the probability of higher-energy forms to stay in the cryogenic sample depends on the barriers separating them from lower-energy forms. If the barriers are low enough (such as $5 \mathrm{~kJ} \mathrm{~mol}^{-1}$ ), and especially if the conformers in question differ only by internal rotation of hydrogen atoms, the higher energy forms will promptly relax, during deposition, into the lower energy counterparts and will not be trapped in a low-temperature matrix (conformational cooling). ${ }^{24-27}$ In this context, the analysis of the energy barriers for conformational isomerization becomes again crucial to the understanding of the conformational composition expected in the matrix isolation experiments. From Fig. 2, it can be seen that only low energy barriers separate the entire family of the cis $\mathrm{O}=\mathrm{C}-\mathrm{O}-\mathrm{H}$ forms. For example, the energy barrier for the IIIa $\rightarrow$ I interconversion (via IIIIb, see Fig. 4) is estimated to be only about $3 \mathrm{~kJ} \mathrm{~mol}^{-1}$; approximately the same barrier heights are also estimated for the IVa $\rightarrow \mathbf{I}$ and IVb $\rightarrow$ I interconversions. Therefore, it can be expected that all the cis $\mathrm{O}=\mathrm{C}-\mathrm{O}-\mathrm{H}$ forms would easily 
convert to the lowest energy conformer I when ALA is deposited in a cryogenic matrix.

It is interesting to analyze the full ALA potential energy surface from the following perspective: "which conformers besides the most stable form of ALA possess isomerization barriers high enough to prevent their relaxation to this conformer, so that they could be observed in a cryogenic matrix?" Obviously, form II satisfies this condition, because in order to be transformed into form $\mathbf{I}$, it requires changing all the three main dihedral angles by $\sim 180^{\circ}$, including rotation around the central $\mathrm{C}-\mathrm{C}$ bond involving heavy atoms, and inversion of the $\mathrm{O}=\mathrm{C}-\mathrm{O}-\mathrm{H}$ dihedral related with a high energy barrier. And indeed, this form has been already observed in a previous matrix-isolation study on alanine. ${ }^{12}$

Further analysis indicates that form VI is another higher energy conformer that satisfies this requirement. Form VI can be transformed into form II by internal rotation around the central C-C bond, via forms VIIIa or VIIIb, with associated barriers of about 8 and $10 \mathrm{~kJ} \mathrm{~mol}^{-1}$, respectively (Fig. 5). It is important to note that such transformation requires movement of heavy atoms and surmounting the steric hindrance of the neighboring matrix atoms. Alternatively, form VI can be connected to form I via internal rotation of the $\mathrm{OH}$ group. Figure 6 shows the calculated potential energy profile for such rotation. The related barrier of $\sim 30 \mathrm{~kJ} \mathrm{~mol}^{-1}$ is also high enough to allow trapping of form VI in a matrix, provided that this conformer could be populated. Since this form has not sufficient thermal population at the sublimation temperature (see Table I), another strategy has to be designed for its population. As it is described in detail below, conformer VI could be efficiently populated in situ by the near-IR excitation of the lower-energy conformer I initially trapped in the matrix from the gas phase. The attempt for the near-IR-induced photogeneration of conformer VI of ALA, and its spectroscopic

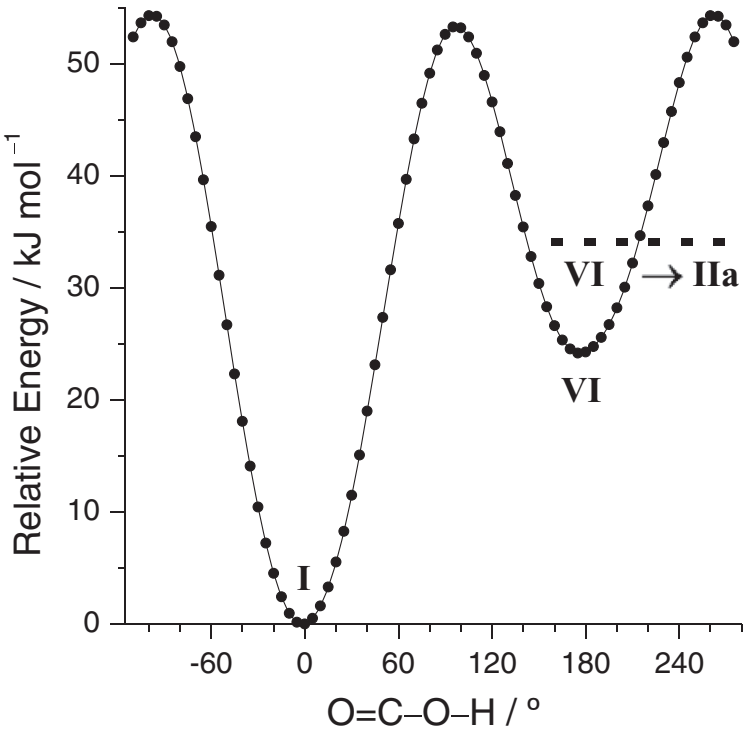

FIG. 6. Relaxed potential energy profile for internal rotation about the $\mathrm{O}=\mathrm{C}-\mathrm{O}-\mathrm{H}$ dihedral angle in ALA connecting conformers I and VI, calculated at the MP2/6-311++G(d,p) level of theory. The horizontal dashed bold line (designated VI $\rightarrow$ IIa) is traced at the same level as in Fig. 5.

characterization, was indeed one of the main objectives of the current work.

\section{B. Infrared spectrum of matrix-isolated L-alanine}

In previous studies, ${ }^{28,29}$ the high-energy forms of carboxylic acids, with the $\mathrm{O}=\mathrm{COH}$ fragment in the trans orientation, were in situ populated in low-temperature matrices, by near-IR excitation of the lower-energy cis conformers to higher $\mathrm{OH}$ stretching vibrational levels, followed by vibrational relaxation involving the isomerization torsional coordinate as acceptor mode. In matrices of noble gases, these

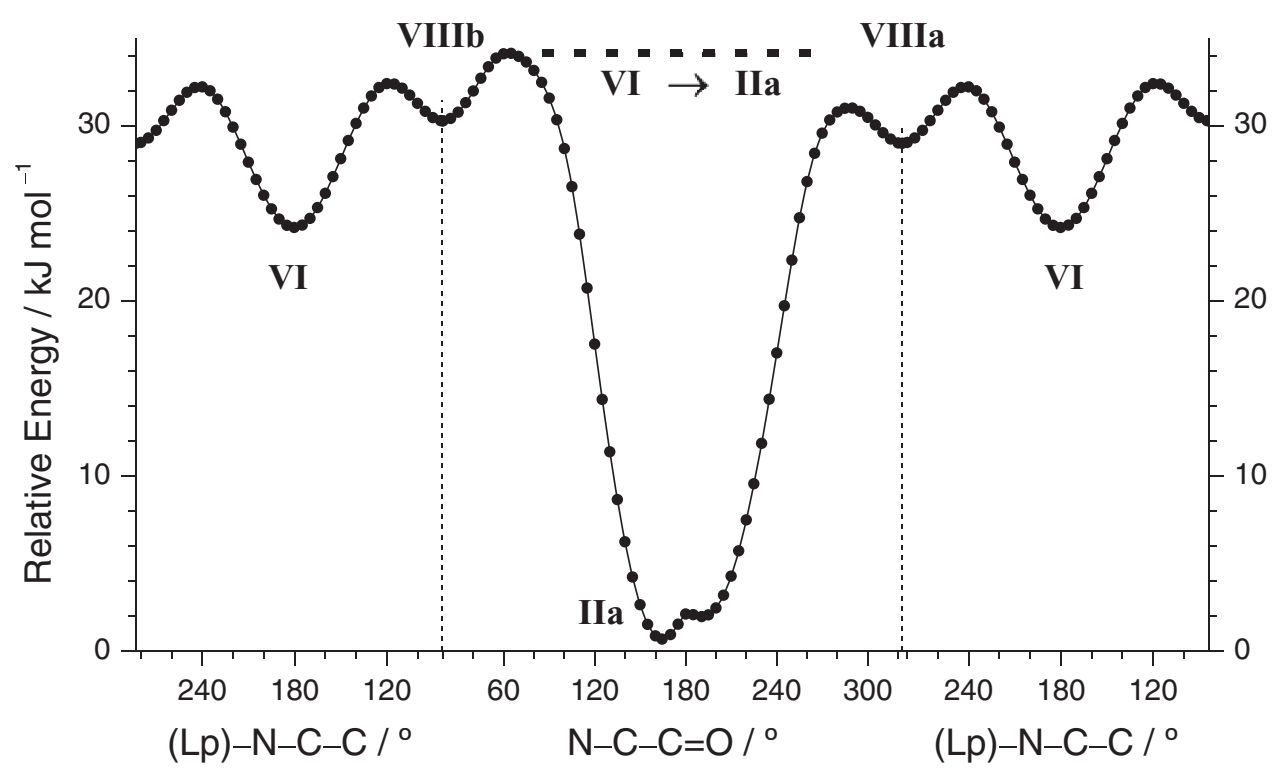

FIG. 5. Relaxed potential energy scan connecting conformers IIa, VI, VIIIa, VIIIb of ALA, calculated at the MP2/6-311++G(d,p) level. The O=C $-\mathrm{O}-\mathrm{H}$ dihedral angle was conserved always in trans orientation. Note the change of reaction coordinate in the middle frame (designated by vertical dashed lines). The left and right frames are identical. The horizontal bold dashed line in the middle frame is traced at the level corresponding to the highest energy saddle point on the way from VI to IIa. 

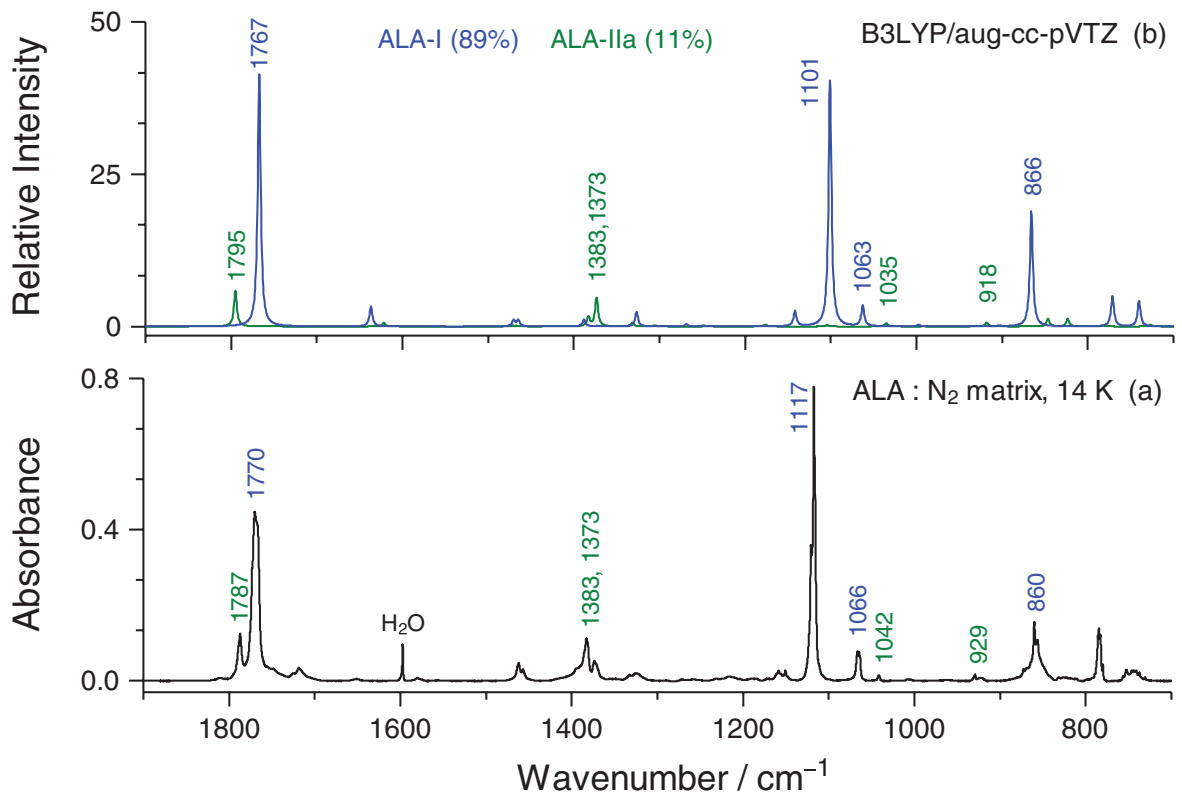

FIG. 7. (a) Experimental fingerprint region of IR spectrum of monomeric ALA isolated in a nitrogen matrix at 14 K. (b) Simulated IR spectrum at the B3LYP/aug-cc-pVTZ level considering the presence of the two conformers, I (blue) and IIa (green) in a ratio of 89:11, respectively. The details of simulation (scaling factors used for calculated frequencies, simulated line shapes) are given in Sec. II E.

high-energy trans forms have usually very short lifetimes. It has been demonstrated that the use of nitrogen as the matrix gas leads to substantial increase of the lifetime of the photogenerated high-energy trans conformers of formic and acetic acids. ${ }^{30}$ Recently, a similar task of population and identification of a high-energy trans $\mathrm{O}=\mathrm{COH}$ conformer has been successfully accomplished for glycine isolated in a nitrogen matrix. ${ }^{31}$ The possibility of generation and spectral characterization of high energy trans $\mathrm{O}=\mathrm{COH}$ conformers of ALA using a similar strategy was explored in the present work.

As it follows from the earlier experiments with alanine isolated in an argon matrix, only conformers I and IIa were found in the freshly deposited matrix samples in the present work. $^{12}$ As discussed in Sec. III A, the absence of other forms can be explained as due to the conformational cooling effect. The gas-phase populations of forms VI-VIII prior to deposition can be neglected, as shown in Table I, while the ways of conformational relaxation of forms III-V, which are predicted to be significantly populated in the gas phase, should be considered. The analysis of the PES of ALA (see Sec. III A) strongly suggests that forms III-V should relax into form $\mathbf{I}$, thus increasing the population of this latter conformer in the matrix. This relaxation is expected to occur due to the low barriers for intramolecular rotation around the (Lp) $-\mathrm{N}-\mathrm{C}-\mathrm{C}$ and $\mathrm{N}-\mathrm{C}-\mathrm{C}=\mathrm{O}$ dihedral angles. On the other hand, the conformational population of form IIa in the matrix will not be augmented by any other form and shall be equal to its population in the gas phase prior to deposition (between 6 and 16\%; see Table I). As a result, the population ratio I:IIa in a matrix could be expected to be approximately around 89:11 (this ratio is equal to the MP2 prediction and is also the average of the ratios estimated from the B3LYP, MP2, and QCSID levels of theory, see Table I).

The experimental infrared spectrum of monomeric ALA isolated in a nitrogen matrix at $14 \mathrm{~K}$ is presented in Fig. 7, together with the B3LYP/cc-pVTZ calculated spectra of conformers I and IIa, weighted by their expected relative populations (89\% I and 11\% IIa). The good agreement between the experimental and the theoretical spectra allows the unambiguous identification of conformers I and IIa in the nitrogen matrix (see Fig. 7). The IR assignment, together with the PED analysis for these two conformers is provided in Tables $\mathrm{S} 2$ and $\mathrm{S} 3$. In the experiments reported in Sec. III C, the bands due to conformer I were depleted upon near-IR irradiation, whereas the bands due to form IIa remained unchanged. This provided additional confidence in distinguishing between the bands due to the two forms in the spectra of the freshly deposited matrices.

\section{Narrowband near-IR generation of a high-energy conformer of L-alanine}

Before the near-IR-induced transformation of conformer I into form VI was attempted, the near-IR absorption spectrum of ALA isolated in a nitrogen matrix had been recorded. In the $v(\mathrm{O}-\mathrm{H})$ overtone region of this spectrum, a broad feature was observed in the $6940-6908 \mathrm{~cm}^{-1}$ range (see below). Since this absorption is much broader than the bandwidth of our irradiation source, we were able to explore the effect of different irradiations by tuning the near-infrared beam at slightly different positions within the broad overtone absorption. In the first experiment, irradiation was performed at $6935 \mathrm{~cm}^{-1}$, which corresponds to the highest-wavenumber component of the $v(\mathrm{O}-\mathrm{H})$ overtone broad multiplet. The changes induced by the near-IR irradiation were monitored by collecting sample's mid-IR spectra.

As result of this near-IR irradiation, selective consumption of the IR bands due to conformer I was observed. Simultaneously, a new set of bands due to a photogenerated species appeared in the IR spectrum. The experimental 

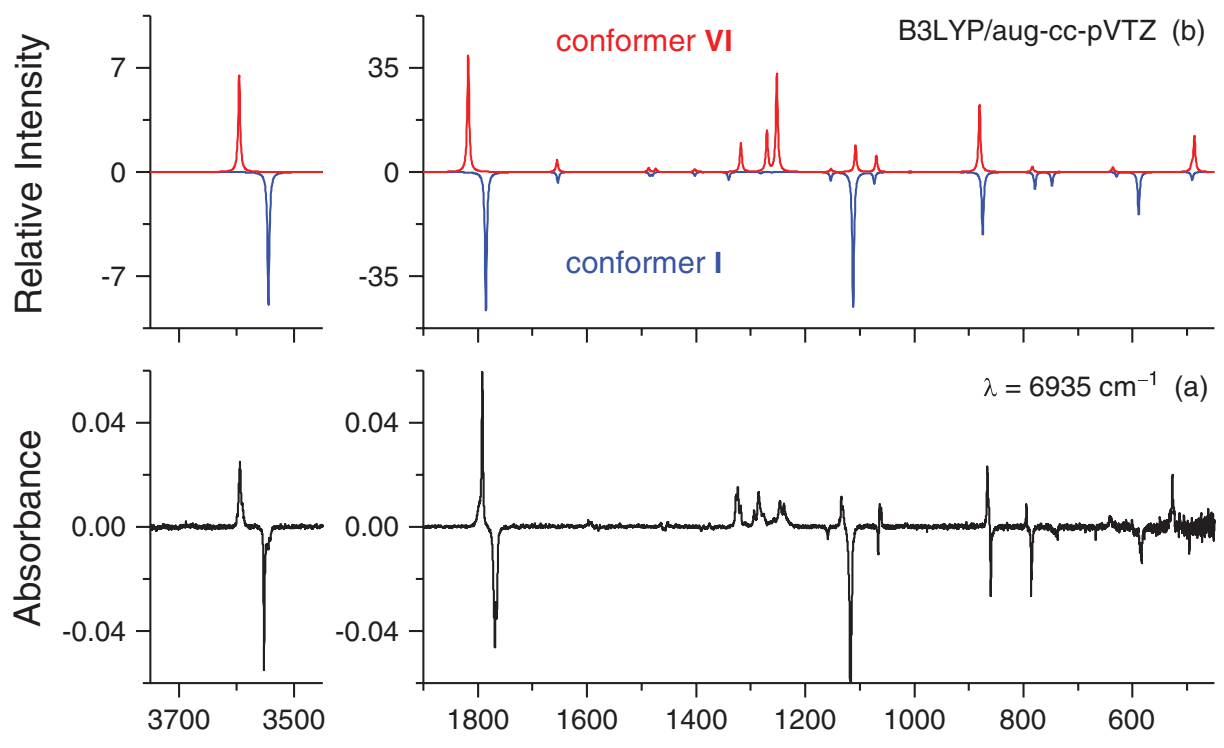

Wavenumber $/ \mathrm{cm}^{-1}$

FIG. 8. (a) Experimental difference IR spectrum; the spectrum obtained after the irradiation at $\lambda=6935 \mathrm{~cm}^{-1}$ "minus" the spectrum of the freshly deposited ALA in a nitrogen matrix at $14 \mathrm{~K}$. (b) Simulated difference IR spectrum at the B3LYP/aug-cc-pVTZ level concerning quantitative production of conformer VI at the expense of conformer $\mathbf{I}$ (intensity ratio 1:1).

difference spectrum, obtained by the subtraction of the spectrum recorded before any irradiation from the spectrum recorded after the near-IR irradiation, is shown in Fig. 8(a). This difference spectrum is very well reproduced by the theoretical spectra predicted for conformer I (the reactant of the phototransformation) and for conformer VI (the photoproduct, see Fig. 8). Conformer IIa stayed unchanged during all near-IR irradiations of ALA isolated in nitrogen matrices (Fig. S3). The assignment of the infrared bands of the hitherto unobserved ALA high-energy conformer VI is shown in Table II.

The presented data undoubtedly demonstrate that nearIR laser excitation of ALA conformer I to its first $v(\mathrm{O}-\mathrm{H})$ overtone induces generation of the high-energy conformer VI (Scheme 1). Especially characteristic are the shifts of the $v(\mathrm{O}-\mathrm{H})$ and $v(\mathrm{C}=\mathrm{O})$ stretching frequencies $\left(\sim 3594 \mathrm{~cm}^{-1}\right.$ and $\sim 1792 \mathrm{~cm}^{-1}$ ) in the photogenerated conformer VI, with respect to the frequencies of the corresponding modes in conformer $\mathbf{I}\left(\sim 3552 \mathrm{~cm}^{-1}\right.$ and $\left.\sim 1768 \mathrm{~cm}^{-1}\right)$. These shifts are in a very good agreement with the shifts between the respective bands in the calculated spectra of $\mathbf{V I}$ and $\mathbf{I}$. The experimental blueshifts of the bands in question are $\sim 42$ and $\sim 24 \mathrm{~cm}^{-1}$, whereas the theoretically predicted blueshifts are $51 \mathrm{~cm}^{-1}$ and $32 \mathrm{~cm}^{-1}$, respectively. The reason for the blueshift of the spectral positions of the bands due to $v(\mathrm{O}-\mathrm{H})$ and $v(\mathrm{C}=\mathrm{O})$
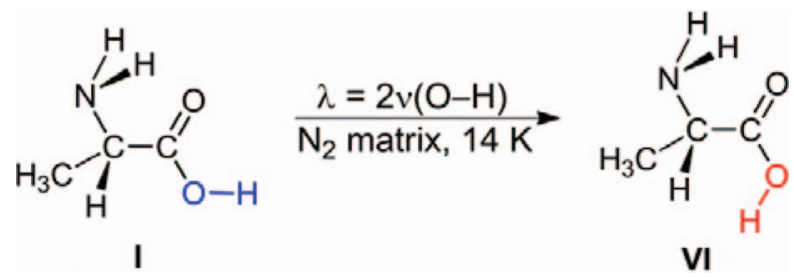

SCHEME 1. NIR-laser excitation to the first $v(\mathrm{O}-\mathrm{H})$ overtone of ALA conformer I induces isomerization to the high-energy conformer VI. stretching vibrations upon the $\mathbf{I} \rightarrow \mathbf{V I}$ transformation is the disruption of the stabilizing intramolecular interaction in the cis $\mathrm{O}=\mathrm{C}-\mathrm{O}-\mathrm{H}$ moiety and shortening of the $\mathrm{OH}$ and $\mathrm{C}=\mathrm{O}$ bonds. Upon cis $\rightarrow$ trans isomerization, the QCISD calculated $\mathrm{OH}$ bond length changes (from $96.56 \mathrm{pm}$ in $\mathbf{I}$ to $96.18 \mathrm{pm}$ in VI), and as it is well-known, the corresponding $\nu \mathrm{OH}$ frequency should increase. ${ }^{32}$ The $\mathrm{C}=\mathrm{O}$ bond also shortens (from $120.70 \mathrm{pm}$ in $\mathbf{I}$ to $120.08 \mathrm{pm}$ in VI), and is in agreement with the observed increase of the $\nu \mathrm{C}=\mathrm{O}$ frequency in form VI. ${ }^{33}$

A similar effect was also previously reported to occur upon near-IR-induced generation of the trans $\mathrm{O}=\mathrm{C}-\mathrm{O}-\mathrm{H}$ conformers of formic or acetic acids at the expense of the corresponding cis conformers. ${ }^{28,29}$ Other relatively intense bands due to conformer VI of ALA appeared at $1324 \mathrm{~cm}^{-1}$, $1286 \mathrm{~cm}^{-1}, 1246 / 1239 \mathrm{~cm}^{-1}, 866 \mathrm{~cm}^{-1}$, and $527 \mathrm{~cm}^{-1}$, also in good agreement with theoretical bands predicted at $1305 \mathrm{~cm}^{-1}\left(\delta_{1} \mathrm{C} 2 \mathrm{H}+\right.$ rock $\left.\mathrm{NH}_{2}\right), 1257 \mathrm{~cm}^{-1}\left(\delta_{1} \mathrm{C} 2 \mathrm{H}\right.$ $+\delta \mathrm{OH}$ ), $1239 \mathrm{~cm}^{-1}(\delta \mathrm{OH}), 872 \mathrm{~cm}^{-1}$ (inv $\mathrm{NH}_{2}$ ), and $482 \mathrm{~cm}^{-1}(\tau \mathrm{OH})$, respectively.

In addition to the irradiation at $6935 \mathrm{~cm}^{-1}$, irradiations at $6920 \mathrm{~cm}^{-1}$ and $6910 \mathrm{~cm}^{-1}$, which are other prominent peaks in the broad multiplet band due to the $v(\mathrm{O}-\mathrm{H})$ overtone of ALA conformer I, were also carried out (Fig. 9). Interestingly, these irradiations led to a selective consumption of ALA conformer $\mathbf{I}$, trapped in different matrix sites, as revealed by the decreasing IR bands of the $v(\mathrm{O}-\mathrm{H})$ fundamental, namely, at $3552 \mathrm{~cm}^{-1}, 3545 \mathrm{~cm}^{-1}$, and $3541 \mathrm{~cm}^{-1}$, respectively. Different matrix microenvironments (sites) surrounding the isolated ALA molecules have a very pronounced effect on the spectral position of the band due to the $v(\mathrm{O}-\mathrm{H})$ stretching vibration. For other IR bands, the environment effect is significantly weaker. Therefore, in other regions of the mid-IR spectrum, it is more difficult to separately observe the spectral manifestations of ALA molecules trapped in different matrix 
TABLE II. Experimental FTIR spectrum (nitrogen matrix at $14 \mathrm{~K}$ ) and calculated (at B3LYP/aug-cc-pVTZ level) vibrational frequencies ( $\mathrm{cm}^{-1}$ ), intensities $\left(\mathrm{km} \mathrm{mol}^{-1}\right)$, and vibrational assignments (PEDs, \%) for ALA conformer VI.

\begin{tabular}{|c|c|c|c|c|}
\hline \multicolumn{2}{|c|}{$\mathrm{N}_{2}$ matrix $(14 \mathrm{~K})^{\mathrm{a}}$} & \multicolumn{2}{|c|}{ B3LYP/aug-cc-pVTZ } & \multirow{2}{*}{$\frac{\text { Assignments }^{\mathrm{b}}}{\operatorname{PED}(\%)}$} \\
\hline$v$ & I & $v$ & I & \\
\hline 3596 & $\operatorname{sh}$ & & & \\
\hline 3594 & $\mathrm{~s}$ & 3595 & 41.1 & vOH (100) \\
\hline 3590 & sh & & & \\
\hline n.o. & & 3383 & 5.6 & $v_{\mathrm{a}} \mathrm{NH}_{2}(99)$ \\
\hline n.o. & & 3316 & 2.9 & $v_{\mathrm{s}} \mathrm{NH}_{2}(98)$ \\
\hline n.o. & & 3056 & 11.9 & $v_{3} \mathrm{CH}_{3}(72), v_{2} \mathrm{CH}_{3}(26)$ \\
\hline 2993 & $\mathrm{vw}$ & 3035 & 23.9 & $v_{2} \mathrm{CH}_{3}(74), v_{3} \mathrm{CH}_{3}(26)$ \\
\hline 2982 & $\mathrm{vw}$ & 2975 & 13.6 & $v_{1} \mathrm{CH}_{3}$ \\
\hline 2934 & vw & 2947 & 22.7 & $\nu \mathrm{C} 2 \mathrm{H}(99)$ \\
\hline 1792 & $\mathrm{~s}$ & 1799 & 250.3 & $\nu \mathrm{C}=\mathrm{O}(87)$ \\
\hline 1593 & vw & 1638 & 25.7 & scis $\mathrm{NH}_{2}(100)$ \\
\hline 1464 & $\mathrm{vw}$ & 1472 & 8.7 & $\delta_{1} \mathrm{CH}_{3}(88)$ \\
\hline 1452 & $\mathrm{vw}$ & 1459 & 6.7 & $\delta_{2} \mathrm{CH}_{3}$ \\
\hline 1375 & vw & 1388 & 6.2 & $\delta_{3} \mathrm{CH}_{3}(64), \delta_{2} \mathrm{C} 2 \mathrm{H}(22)$ \\
\hline n.o. & & 1379 & 1.0 & $\delta_{2} \mathrm{C} 2 \mathrm{H}(50), \delta_{3} \mathrm{CH}_{3}(33)$, rock $\mathrm{NH}_{2}(16)$ \\
\hline 1327 & $\mathrm{~m}$ & & & \\
\hline 1324 & $\mathrm{~m}$ & 1305 & 60.7 & $\delta_{1} \mathrm{C} 2 \mathrm{H}(51)$, rock $\mathrm{NH}_{2}(10)$ \\
\hline 1318 & w & & & \\
\hline 1294 & w & & & \\
\hline 1286 & $\mathrm{~m}$ & 1257 & 87.7 & $\delta_{1} \mathrm{C} 2 \mathrm{H}(22), \delta \mathrm{OH}(18)$, rock $\mathrm{NH}_{2}(14)$ \\
\hline 1276 & $\mathrm{w}$ & & & \\
\hline 1246 & $\mathrm{~m}$ & & & \\
\hline 1239 & $\mathrm{~m}$ & 1239 & 209.3 & $\delta \mathrm{OH}(43)$, rock $\mathrm{NH}_{2}(19)$ \\
\hline n.o. & & 1141 & 6.4 & $\nu \mathrm{CN}(35), \delta_{2} \mathrm{C} 2 \mathrm{H}(12), \nu \mathrm{C} 2 \mathrm{C} 10(11)$ \\
\hline 1134 & $\mathrm{~m}$ & 1097 & 56.9 & $\nu \mathrm{C}-\mathrm{O}(52), \delta \mathrm{OH}(18)$ \\
\hline 1131 & $\mathrm{w}$ & & & \\
\hline 1063 & $\mathrm{w}$ & 1059 & 35.5 & $\delta_{5} \mathrm{CH}_{3}(24), \delta_{4} \mathrm{CH}_{3}(20), \delta_{1} \mathrm{C} 2 \mathrm{H}(11)$ \\
\hline 1061 & $\mathrm{w}$ & & & \\
\hline n.o. & & 998 & 1.5 & $\operatorname{rock} \mathrm{NH}_{2}(26), \delta_{5} \mathrm{CH}_{3}(20), \delta_{4} \mathrm{CH}_{3}(18), \nu \mathrm{C} 2 \mathrm{C} 10$ \\
\hline n.o. & & 899 & 1.2 & $\nu \mathrm{C} 2 \mathrm{C} 10(35), \delta_{4} \mathrm{CH}_{3}(24), \nu \mathrm{CN}(21)$ \\
\hline 866 & $\mathrm{~s}$ & 872 & 143.7 & $\operatorname{inv} \mathrm{NH}_{2}(75), v \mathrm{CN}(11)$ \\
\hline 795 & $\mathrm{w}$ & 776 & 11.4 & $\nu \mathrm{C} 2 \mathrm{C} 3(32)$, scis $\mathrm{OCO}(14), \delta_{5} \mathrm{CH}_{3}(12)$ \\
\hline n.o. & & 727 & 0.7 & $\tau_{2} \mathrm{OCO}(59), v \mathrm{C} 2 \mathrm{C} 10(13)$ \\
\hline 641 & $\mathrm{vw}$ & 630 & 10.6 & scis OCO (34), rock OCO $(16), v \mathrm{C}-\mathrm{O}(11), \delta_{1} \mathrm{CCN}(11)$ \\
\hline n.o. & & 487 & 12.5 & $\operatorname{scis} \operatorname{OCO}(20)$, rock OCO $(17), \delta_{1} \mathrm{CCN}(11), \delta_{3} \mathrm{CCN}(11)$ \\
\hline 527 & $\mathrm{~m}$ & 482 & 76.9 & $\tau \mathrm{OH}(97)$ \\
\hline n.i. & & 369 & 12.1 & $\delta_{3} \mathrm{CCN}(52), v \mathrm{C} 2 \mathrm{C} 3(10)$ \\
\hline n.i. & & 297 & 13.5 & $\delta_{1} \mathrm{CCN}(35)$, rock OCO (28), twist $\mathrm{NH}_{2}(11)$ \\
\hline n.i. & & 235 & 10.4 & $\delta_{2} \mathrm{CCN}(63), \tau_{2} \mathrm{OCO}(16)$, rock OCO $(13)$ \\
\hline n.i. & & 221 & 2.4 & twist $\mathrm{NH}_{2}(88)$ \\
\hline n.i. & & 187 & 46.5 & twist $\mathrm{CH}_{3}(89)$ \\
\hline n.i. & & 50 & 6.7 & $\tau_{1} \mathrm{OCO}(97)$ \\
\hline
\end{tabular}

${ }^{a}$ FTIR spectrum of ALA conformer VI generated upon NIR-laser irradiation at $\lambda=6935 \mathrm{~cm}^{-1}$. For multiplet bands, bold wavenumbers designate the more intense components. The calculated frequencies were scaled by 0.950 and 0.980 , above and below $3300 \mathrm{~cm}^{-1}$, respectively. Experimental intensities are presented in qualitative terms: $\mathrm{s}=$ strong, sh $=$ shoulder, $\mathrm{m}=$ medium, $\mathrm{w}=$ weak, and $\mathrm{vw}=$ very weak. Abbreviations, n.o. - not observed; n.i. - not investigated .

${ }^{\text {b} P E D ' s ~ l o w e r ~ t h a n ~} 10 \%$ are not included. Definition of internal coordinates is given in Table S1. ${ }^{42}$

sites and, consequently, to observe experimentally the effect of site-selectivity in the performed near-IR irradiation series of experiments.

The present observations suggest that under the reported experimental conditions, the dominating process occurring upon near-IR excitation of the most stable conformer $\mathbf{I}$ of the compound was its transformation to form VI, differing from I essentially by the half-turn rotation of the $\mathrm{OH}$ group (Scheme 1). No new IR bands, appearing upon near-IR irradiation, could be assigned to any other conformation of ALA but the form VI. This shows that the hindrance induced by the rigid environment of solid nitrogen considerably hampers intramolecular rotations involving significant displacements of fragments of the molecule heavier than a hydrogen atom.

\section{The decay mechanism of L-alanine high-energy conformer VI in a nitrogen matrix}

Remarkably, after the generation of the high-energy conformer VI of ALA at the expense of conformer I (by 

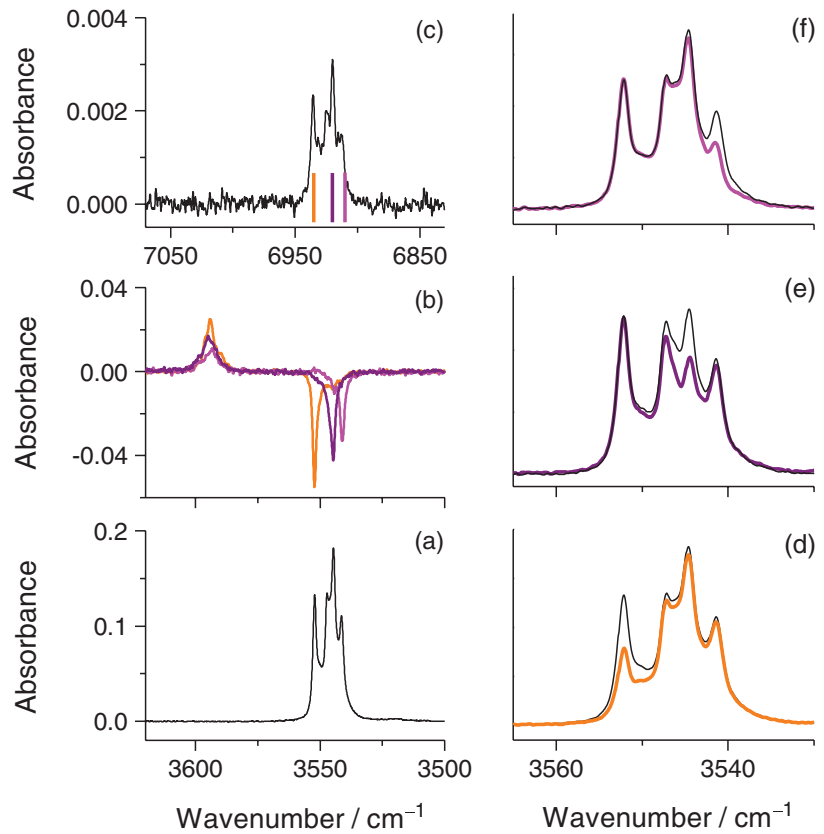

FIG. 9. (a) Experimental IR spectrum of monomeric ALA isolated in a nitrogen matrix at $14 \mathrm{~K}$, showing the $v(\mathrm{O}-\mathrm{H})$ region of conformer $\mathbf{I}$. (b) Experimental difference IR spectra (in the $v(\mathrm{O}-\mathrm{H})$ region) obtained after irradiations with $\lambda=6935 \mathrm{~cm}^{-1}$ (orange), $6920 \mathrm{~cm}^{-1}$ (purple), and $6910 \mathrm{~cm}^{-1}$ (magenta) "minus" the spectrum prior to the corresponding irradiation, see (d)-(f). (c) Experimental near-IR spectrum of monomeric ALA isolated in a nitrogen matrix at $14 \mathrm{~K}$, showing the $2 v(\mathrm{O}-\mathrm{H})$ region of conformer $\mathbf{I}$. The color bars (orange $=6935 \mathrm{~cm}^{-1}$, purple $=6920 \mathrm{~cm}^{-1}$, and magenta $=6910$ $\mathrm{cm}^{-1}$ ) indicate the positions where the laser output was tuned. (d)-(f) Experimental IR spectra showing the $v(\mathrm{O}-\mathrm{H})$ region of conformer I before (black) and after irradiation with $\lambda=6935 \mathrm{~cm}^{-1}$ (orange), $6920 \mathrm{~cm}^{-1}$ (purple), and $6910 \mathrm{~cm}^{-1}$ (magenta), respectively.

narrowband near-IR irradiation with wavenumbers of 6935 $\mathrm{cm}^{-1}, 6920 \mathrm{~cm}^{-1}$, or $6910 \mathrm{~cm}^{-1}$ ), the decay of conformer VI back to conformer I was observed in a time scale of minutes. While, for the matrix kept in the dark, the population of VI was decreasing and the population of I was increasing, no changes were observed in the IR bands ascribed to IIa.

The calculated barrier for the $\mathbf{V I} \rightarrow \mathbf{I}$ isomerization was estimated as $\sim 30 \mathrm{~kJ} \mathrm{~mol}^{-1}$ (Fig. 6). In a matrix at $14 \mathrm{~K}$, such isomerization cannot occur by the classic thermal (overbarrier) mechanism. Thus, a different phenomenon should be responsible for the observed relaxation of conformer VI to conformer I. Earlier studies on cytosine isolated in a lowtemperature argon matrix indicated that not only the near-IR excitation of the $v(\mathrm{O}-\mathrm{H})$ overtone (leading to the $v=2$ vibrational state) but also the excitation to the first excited state of the $v(\mathrm{O}-\mathrm{H})$ stretching vibration (including that promoted by the broadband mid-IR source of spectrometer) induced interconversion between the two amino-hydroxy conformers of the compound. ${ }^{34}$ Such occurrence was rationalized in terms of an over-the-barrier process. The energy of the first excited state of the $v(\mathrm{O}-\mathrm{H})$ stretching vibration is higher than the barrier estimated for the conformational isomerization of the amino-hydroxy forms of cytosine. ${ }^{34}$ In ALA conformer VI the corresponding $v(\mathrm{O}-\mathrm{H})$ stretching energy is $\sim 43 \mathrm{~kJ} \mathrm{~mol}^{-1}$ (or $3596 / 3594 \mathrm{~cm}^{-1}$, Table I) which is above the barrier separating form VI from $\mathbf{I}\left(\sim 30 \mathrm{~kJ} \mathrm{~mol}^{-1}\right.$, see Fig. 6.)

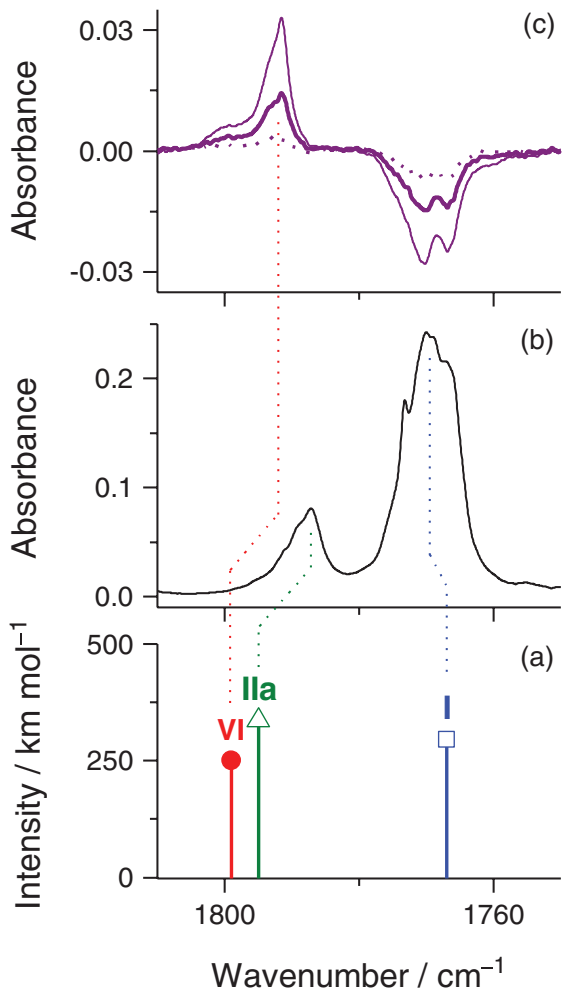

FIG. 10. (a) Theoretical infrared spectra of conformers VI $(\bullet$, red), IIa $(\triangle$, green), and I ( $\square$, blue) calculated at the B3LYP/aug-cc-pVTZ level. (b) Experimental IR spectrum of monomeric ALA isolated in a nitrogen matrix at $14 \mathrm{~K}$, in the $v(\mathrm{C}=\mathrm{O})$ region, before irradiation. (c) Experimental spectra obtained by subtracting spectrum shown in frame "b": (thin line) from the spectrum collected immediately after $20 \mathrm{~min}$ of irradiation at $\lambda=6920$ $\mathrm{cm}^{-1}$; (bold line) from the spectrum collected $15 \mathrm{~min}$ after the irradiation; (dotted line) from the spectrum collected $40 \mathrm{~min}$ after the irradiation. All spectra shown in this figure were collected with filter transmitting only light below $2100 \mathrm{~cm}^{-1}$. Colored dotted lines across frames show the assignment of the $v(\mathbf{C}=\mathbf{O})$ band of conformers $\mathbf{V I}$, IIa, and $\mathbf{I}$.

To exclude excitation to the first excited state of the $v(\mathrm{O}-\mathrm{H})$ stretching vibration as a cause of the $\mathbf{V I} \rightarrow$ I transformation in ALA, the decay of conformer VI was monitored using a filter transmitting only light with wavenumbers lower than $2100 \mathrm{~cm}^{-1}$ (or, in other terms, only energies below $25 \mathrm{~kJ} \mathrm{~mol}^{-1}$ ), after the near-IR irradiation stopped. With this approach, the spontaneous depopulation of the photogenerated conformer VI and the concomitant repopulation of conformer I were measured as a function of time. Figure 10(c) shows three spectra collected at different stages following irradiation at $6920 \mathrm{~cm}^{-1}$. Integrated intensities of the IR bands due to the $v(\mathbf{C}=\mathbf{O}$ ) vibrations in VI and in $\mathbf{I}$ (those shown in Fig. 10(c)) were used to evaluate the changes in relative populations of these two forms. In the decay kinetics presented in Fig. 11, the relative population of form VI estimated from the first spectrum recorded immediately after irradiation was assumed to be unity. Fitting the experimental data by single exponential decay kinetics (Fig. 11) gives an average halflife time $\left(\tau_{1 / 2}\right)$ of $\sim 15 \mathrm{~min}$ for the depopulation of ALA conformer VI in the dark and at $14 \mathrm{~K}$ (see also Tables S4 and S5).

The relatively short lifetime of the high-energy conformer VI is in agreement with the observation that it was 


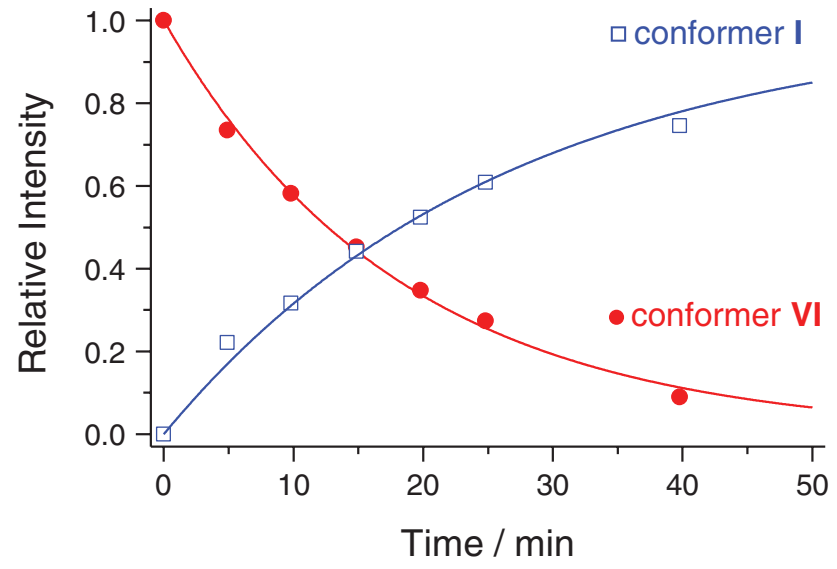

FIG. 11. Decay kinetics of conformer VI of ALA in a $\mathrm{N}_{2}$ matrix at $14 \mathrm{~K}$, followed after irradiation of sample at $\lambda=6920 \mathrm{~cm}^{-1}$ (the first $\nu \mathrm{O}-\mathrm{H}$ overtone of conformer I). The circles and squares $(-$ and $\square$ ) represent the experimental measures of the evolution of conformers VI and $\mathbf{I}$, respectively, by using their $v(\mathrm{C}=\mathrm{O})$ band, which was recorded with IR filter transmitting light only below $2100 \mathrm{~cm}^{-1}$. The red line represents the fitted single exponential decay (decreasing form) curve of conformer VI and the blue line represents the single exponential decay (increasing form) curve of conformer I (see also Tables S4 and S5).

not possible to totally convert I into VI by near-IR irradiation (Figs. 9(d)-9(f)). A fast recovery of depleted form $\mathbf{I}$ allowed a possibility of studying transformations (and decays) induced by different near-IR excitations on the same sample starting from the same common point (where the entire form VI is absent). Different packing sites were selectively pumped inducing excitations in different components of the overtone multiplet. The observed decay kinetics of conformer VI were very similar for all trapping sites. Spontaneous back reaction VI $\rightarrow$ I has the direction opposite to the near-IR-induced I $\rightarrow$ VI conversion. Hence, it seems possible that these two processes, once occurring simultaneously, lead to a stationary population ratio.

The most plausible rationalization for the mechanism of back isomerization of ALA conformer VI to conformer $\mathbf{I}$, in the dark at $14 \mathrm{~K}$, is the occurrence of a tunneling decay, as reported previously for other matrixisolated molecules containing the carboxylic fragment, such as formic, ${ }^{35}$ acetic, ${ }^{29,36}$ propionic, ${ }^{37}$ 2-chloropropionic, ${ }^{38}$ benzoic $^{39,40}$ acids, glycine, ${ }^{31}$ and other systems, for example, hydroxycarbene. ${ }^{41}$ Actually, if thermal isomerization is involved, form VI could be transformed into form IIa (via forms VIIIa or VIIIb) instead of isomerization into form I, since this process has a much lower energy barrier (i.e., $8-10 \mathrm{~kJ} \mathrm{~mol}^{-1}$ versus $30 \mathrm{~kJ} \mathrm{~mol}^{-1}$, respectively; as compared graphically in Figs. 5 and 6).

The obtained experimental evidence shows that the barrier of $\sim 30 \mathrm{~kJ} \mathrm{~mol}^{-1}$, related with isomerization of the $\mathrm{OH}$ group in alanine, is crossed on a time scale of several minutes. This evidence prompts to extend a similar reasoning to the movement of light atoms about lower barriers. Namely, the barriers of $\sim 5-8 \mathrm{~kJ} \mathrm{~mol}^{-1}$, related with movement of light atoms in the $\mathrm{NH}_{2}$ group, should be overcome too (and much faster), if the remaining experimental conditions are comparable. This explains the non-observation of conformers differing only by the $\mathrm{NH}_{2}$ group orientation from their lower energy counterparts, i.e., significantly reduces the number of structures amenable to observation, in principle (both in alanine and in other similar molecules).

\section{CONCLUSIONS}

Two conformers of L-alanine were detected for the monomers of the compound isolated in a low-temperature nitrogen matrix. The extensive theoretical study of the potential energy surface of the compound led to location of 12 minima. According to the theoretical predictions, seven L-alanine conformers should be non-negligibly populated in the gas phase. However, due to low barriers separating these conformers of L-alanine from lower energy conformers, they collapse to these latter when the molecules are cooled during formation of a low-temperature matrix. A never experimentally observed before high-energy conformer (VI), differing from the most stable form (I) of L-alanine only by rotation of the $\mathrm{OH}$ group, was photogenerated by irradiation of the samples with near-IR light. Thanks to the narrowband character of the light beam used for irradiation, it was possible to carry out the photoinduced conformational transformation in a siteselective way. Following the near-IR-induced conformational conversion, the spontaneous decay of the photoproduct and the repopulation of the most stable conformer of L-alanine $(\mathbf{V I} \rightarrow \mathbf{I})$ were observed for a nitrogen matrix kept in the dark and at $14 \mathrm{~K}$. The mechanism of this process was shown to involve a hydrogen atom tunneling. The half-life time of this process was estimated as $\sim 15 \mathrm{~min}$.

\section{ACKNOWLEDGMENTS}

This work was supported by the Portuguese "Fundação para a Ciência e a Tecnologia" (FCT) Research Project Nos. PTDC/QUI-QUI/111879/2009 and PTDC/QUIQUI/118078/2010, FCOMP-01-0124-FEDER-021082, cofunded by QREN-COMPETE-UE. The current study was also supported by the National Science Center (Poland) under Grant No. 2011/01/B/ST4/00718 and by the European Community's Seventh Framework Programme under the Grant Agreement No. 228334. C.M.N. acknowledges FCT for the post-doctoral grant (No. SFRH/BPD/86021/2012).

${ }^{1}$ C. W. Pratt, D. Voet, and J. G. Voet, Fundamentals of Biochemistry: Life at the Molecular Level (Jonh Wiley and Sons, 2008).

${ }^{2}$ A. Kessel and N. Ben-Tal, Introduction to Proteins: Structure, Function, and Motion (CRC Press, 2010).

${ }^{3}$ S. Gronert and R. A. J. O'Hair, J. Am. Chem. Soc. 117, 2071 (1995).

${ }^{4}$ M. Cao, S. Newton, J. Pranata, and L. Schäfer, J. Mol. Struct. 332, 251 (1995).

${ }^{5}$ P. Godfrey, R. Brown, and F. Rodgers, J. Mol. Struct. 376, 65 (1996).

${ }^{6}$ A. G. Császár, J. Phys. Chem. 100, 3541 (1996).

${ }^{7}$ P. Selvarengan and P. Kolandaivel, J. Mol. Struct.:THEOCHEM 671, 77 (2004).

${ }^{8}$ R. Maul, F. Ortmann, M. Preuss, K. Hannewald, and F. Bechstedt, J. Comput. Chem. 28, 1817 (2007).

${ }^{9}$ H. M. Jaeger, H. F. Schaefer III, J. Demaison, A. G. Császár, and W. D. Allen, J. Chem. Theory Comput. 6, 3066 (2010).

${ }^{10}$ R. A. Cormanich, L. C. Ducati, and R. Rittner, J. Mol. Struct. 1014, 12 (2012). 
${ }^{11}$ P. D. Godfrey, S. Firth, L. D. Hatherley, R. D. Brown, and A. P. Pierlot, J. Am. Chem. Soc. 115, 9687 (1993).

${ }^{12}$ S. G. Stepanian, I. D. Reva, E. D. Radchenko, and L. Adamowicz, J. Phys. Chem. A 102, 4623 (1998).

${ }^{13}$ I. Powis, J. Phys. Chem. A 104, 878 (2000).

${ }^{14}$ S. Blanco, A. Lesarri, J. C. López, and J. L. Alonso, J. Am. Chem. Soc. 126, 11675 (2004).

${ }^{15}$ R. Linder, K. Seefeld, A. Vavra, and K. Kleinermanns, Chem. Phys. Lett. 453, 1 (2008).

${ }^{16}$ Y. Hirata, S. Kubota, S. Watanabe, T. Momose, and K. Kawaguchi, J. Mol. Spectrosc. 251, 314 (2008).

${ }^{17}$ R. M. Balabin, Phys. Chem. Chem. Phys. 12, 5980 (2010).

${ }^{18}$ H. Farrokhpour, F. Fathi, and A. Naves De Brito, J. Phys. Chem. A 116, 7004 (2012).

${ }^{19}$ M. J. Frisch, G. W. Trucks, H. B. Schlegel et al., GaUssian 09, Revision A.02, Gaussian, Inc., Wallingford, CT, 2009.

${ }^{20}$ K. K. Irikura, Program SYNSPEC, National Institute of Standards and Technology, Gaithersburg, USA.

${ }^{21}$ G. Keresztury and G. Jalsovszky, J. Mol. Struct. 10, 304 (1971).

${ }^{22}$ H. Rostkowska, L. Lapinski, and M. J. Nowak, Vib. Spectrosc. 49, 43 (2009).

${ }^{23}$ P. Pulay, G. Fogarasi, F. Pang, and J. E. Boggs, J. Am. Chem. Soc. 101, 2550 (1979).

${ }^{24}$ I. D. Reva, S. G. Stepanian, L. Adamowicz, and R. Fausto, Chem. Phys. Lett. 374, 631 (2003).

${ }^{25}$ I. Reva, A. Simão, and R. Fausto, Chem. Phys. Lett. 406, 126 (2005).

${ }^{26}$ I. D. Reva, A. J. Lopes Jesus, M. T. S. Rosado, R. Fausto, M. E. Eusébio, and J. S. Redinha, Phys. Chem. Chem. Phys. 8, 5339 (2006).

${ }^{27}$ M. T. S. Rosado, A. J. Lopes Jesus, I. D. Reva, R. Fausto, and J. S. Redinha, J. Phys. Chem. A 113, 7499 (2009).

${ }^{28}$ M. Pettersson, J. Lundell, L. Khriachtchev, and M. Räsänen, J. Am. Chem. Soc. 119, 11715 (1997).

${ }^{29}$ E. M. S. Maçôas, L. Khriachtchev, M. Pettersson, R. Fausto, and M. Räsänen, J. Am. Chem. Soc. 125, 16188 (2003).

${ }^{30}$ S. Lopes, A. V. Domanskaya, R. Fausto, M. Räsänen, and L. Khriachtchev, J. Chem. Phys. 133, 144507 (2010).
${ }^{31}$ G. Bazsó, G. Magyarfalvi, and G. Tarczay, J. Phys. Chem. A 116, 10539 (2012).

${ }^{32}$ J. Demaison, M. Herman, and J. Lievin, Int. Rev. Phys. Chem. 26, 391 (2007).

${ }^{33}$ K. Takei, R. Takahashi, and T. Noguchi, J. Phys. Chem. B 112, 6725 (2008).

${ }^{34}$ I. Reva, M. J. Nowak, L. Lapinski, and R. Fausto, J. Chem. Phys. 136, 064511 (2012).

${ }^{35}$ M. Pettersson, E. M. S. Maçôas, L. Khriachtchev, J. Lundell, R. Fausto, and M. Räsänen, J. Chem. Phys. 117, 9095 (2002).

${ }^{36}$ E. M. S. Maçôas, L. Khriachtchev, M. Pettersson, R. Fausto, and M. Räsänen, J. Chem. Phys. 121, 1331 (2004).

${ }^{37}$ E. M. S. Maçôas, L. Khriachtchev, M. Pettersson, R. Fausto, and M. Räsänen, J. Phys. Chem. A 109, 3617 (2005).

${ }^{38}$ G. Bazsó, S. Góbi, and G. Tarczay, J. Phys. Chem. A 116, 4823 (2012).

${ }^{39}$ S. Amiri, H. P. Reisenauer, and P. R. Schreiner, J. Am. Chem. Soc. 132, 15902 (2010).

${ }^{40}$ S. Nishino and M. Nakata, J. Phys. Chem. A 111, 7041 (2007).

${ }^{41}$ P. R. Schreiner, H. P. Reisenauer, F. C. Pickard IV, A. C. Simmonett, W. D. Allen, E. Mátyus, and A. G. Császár, Nature (London) 453, 906 (2008).

${ }^{42}$ See supplementary material at http://dx.doi.org/10.1063/1.4795823 for: Table S1. Internal coordinates used in the normal modes analysis for conformers of ALA; Table S2. Experimental FTIR spectrum, calculated and vibrational assignments for ALA conformer I; Table S3. Experimental FTIR spectrum, calculated and vibrational assignments for ALA conformer IIa; Tables S4 and S5. Data of the evolution of ALA conformers VI and I, immediately after the irradiation of the $\mathrm{O}-\mathrm{H}$ overtone of conformer I; Fig. S1. Graphical representation of ALA conformers; Fig. S2. Relaxed onedimensional potential energy profiles calculated for ALA, at the MP2/6$311++\mathrm{G}(\mathrm{d}, \mathrm{p})$ and QCISD/6-311++G(d,p) levels, in the vicinity of structure II; Fig. S3. Experimental IR spectrum of monomeric ALA isolated in a nitrogen matrix at $14 \mathrm{~K}$ compared with the spectrum obtained after irradiation with $\lambda=6935 \mathrm{~cm}^{-1}$ and with the simulated spectrum of conformer IIa at the B3LYP/aug-cc-pVTZ level; Cartesian coordinates, vibrational frequencies, and infrared intensities for of all minimum-energy structures of ALA calculated at MP2/6-311++G(d,p), B3LYP/aug-cc-pVTZ, and QCISD/6-311++G(d,p) levels. 